\title{
Synthesis of Tri-functional Bis-azide Photoaffinity Probe
}

\author{
Larry L. Klein*, Valentina Petukhova \\ Institute for Tuberculosis Research, University of Illinois at Chicago, Chicago, USA
}

833 S Wood Street, Chicago IL 60612, 1lk@uic.edu

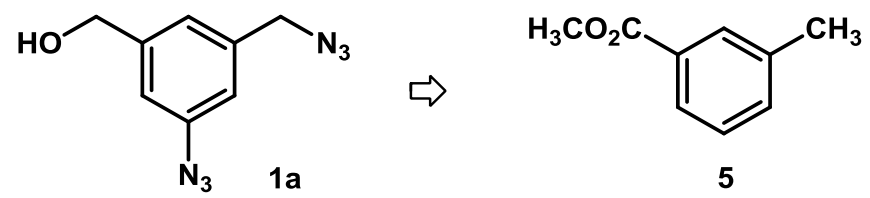

\begin{abstract}
Methyl 3-azidomethyl-5-azido-benzoate (1b) and its corresponding hydroxymethyl reduction product (1a) have been utilized for the synthesis of valuable non-radioactive photoaffinity probes. Previous preparations of (1a) depend upon a non-selective monoactivation of a bis-1,3-hydroxymethylaryl intermediate, leading to the expected statistical range of products/starting material. We report an alternate synthetic approach to these 1,3,5-trisubstituted molecules using recently described $\mathrm{C}$-H activation and boronate refunctionalization methods.
\end{abstract}

Keywords: photoaffinity; borylation; azide

\section{INTRODUCTION}

Photoaffinity labeling is a useful tool for investigation of ligand-protein interaction. ${ }^{[1]}$ This process involves the use of a binding substrate (probe) which has been modified with a photoactive functional group. Upon irradiation, this group produces a chemoreactive center (e.g. carbene, nitrene) which can form a covalent bond to proximal atoms 
in the protein thus establishing these proteins as potential binding targets for this

molecule. The actual photoactive groups have included benzophenones, ${ }^{[2]}$ diazirines, ${ }^{[1,3]}$ and azides, ${ }^{[4]}$ among others, with the former being less reactive/more selective, and the latter being more reactive/less selective. Various non-radioactive methods have been used to identify these proteins and usually involves a second chemical connection ("tagging") to rhodamines/fluoresceins, ${ }^{[5]}$ biotin, ${ }^{[6]}$ or fluorous-related ${ }^{[7]}$ derivatives in order to isolate the "tagged" protein via visual or affinity-binding techniques.

\section{DISCUSSION}

In recent years, molecules containing the bisazide moiety such as 1a-c (Figure 1), have been utilized as a photo-affinity probes ${ }^{[4]}$ to identify or characterize proteins involved in calcium ion release ${ }^{[8]}$ and HDAC8 inhibitors. ${ }^{[9]}$ In these cases, the ester or sulfonate group functionality serves as this probe's point of attachment via amide or ether linkage, respectively. For this tagging process to be successful, the attachment must occur onto the ligand at sites which do not interfere with binding to the protein. The aryl azide in 1c is selectively photoactivated in the presence of the more stable benzyl azide ${ }^{[4]}$ and forms the covalent link to the protein. Subsequent Huisgen reaction of the benzyl azide with a pendant alkyne group of the visualizing agent is carried out to assist in the detection/isolation of the probe-linked protein. The 1,3,5-substitution pattern was key to isolating the three orthogonal synthetic processes for this novel moiety.

Figure 1. Structure of photo-affinity label.

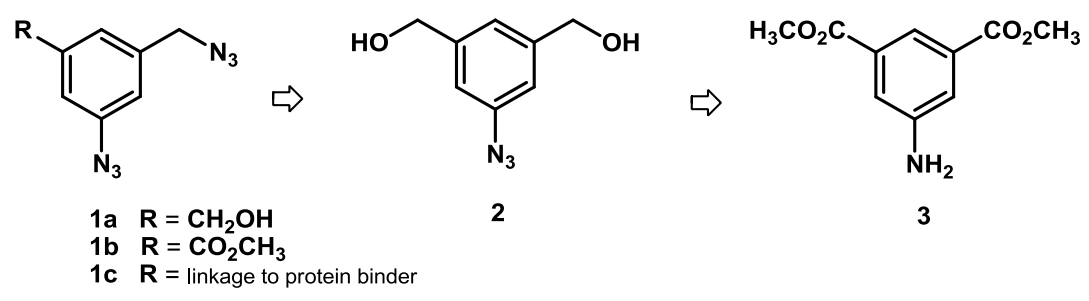


The synthesis of probes $\mathbf{1 a}$ and $\mathbf{1 b}$ have been reported ${ }^{[4]}$ and modified in later work. ${ }^{[10]}$ In both cases, the key limiting reaction involves a statistical mono-functionalization of the intermediate diol $\mathbf{2}$ which, in turn, is prepared from commercially available diester, $\mathbf{3}$. We were in need of this useful probe and realized that this non-selective reaction of $\mathbf{2}$ could be avoided through the use of recently evolving technologies of $\mathrm{C}-\mathrm{H}$ activation and boronate-refunctionalization and so, report an alternate synthesis of $\mathbf{1}$ herein. Malezcka and Smith ${ }^{[11]}$ and Hartwig ${ }^{[12]}$ reported an efficient regioselective formation of 1,3,5-trisubstituted aromatic molecules via the use of iridium-based catalyzed borylation reaction. Treatment of methyl 3-methylbenzoate under modified borylation conditions ${ }^{[13]}$ led to a good yield of the desired regioisomer, 6 (Scheme 1). ${ }^{[14]}$ With this key intermediate in hand, we found that radical bromination ${ }^{[15]}$ could be successfully carried out to afford 7 containing a small amount of the purported $\alpha, \alpha$-dibromide after recrystallization from cyclohexane. Due to some instability, this material was used directly for subsequent bromide displacement with sodium azide to give the corresponding monoazide, $\mathbf{8}$. Recent work in the area of copper catalyzed refunctionalization of boronates with a wide variety of nucleophiles ${ }^{[16]}$ suggested that the aryl azide could be formed in a subsequent step from substrates such as $\mathbf{8}$.

Scheme 1. Alternate synthesis of $\mathbf{1 a}$. 


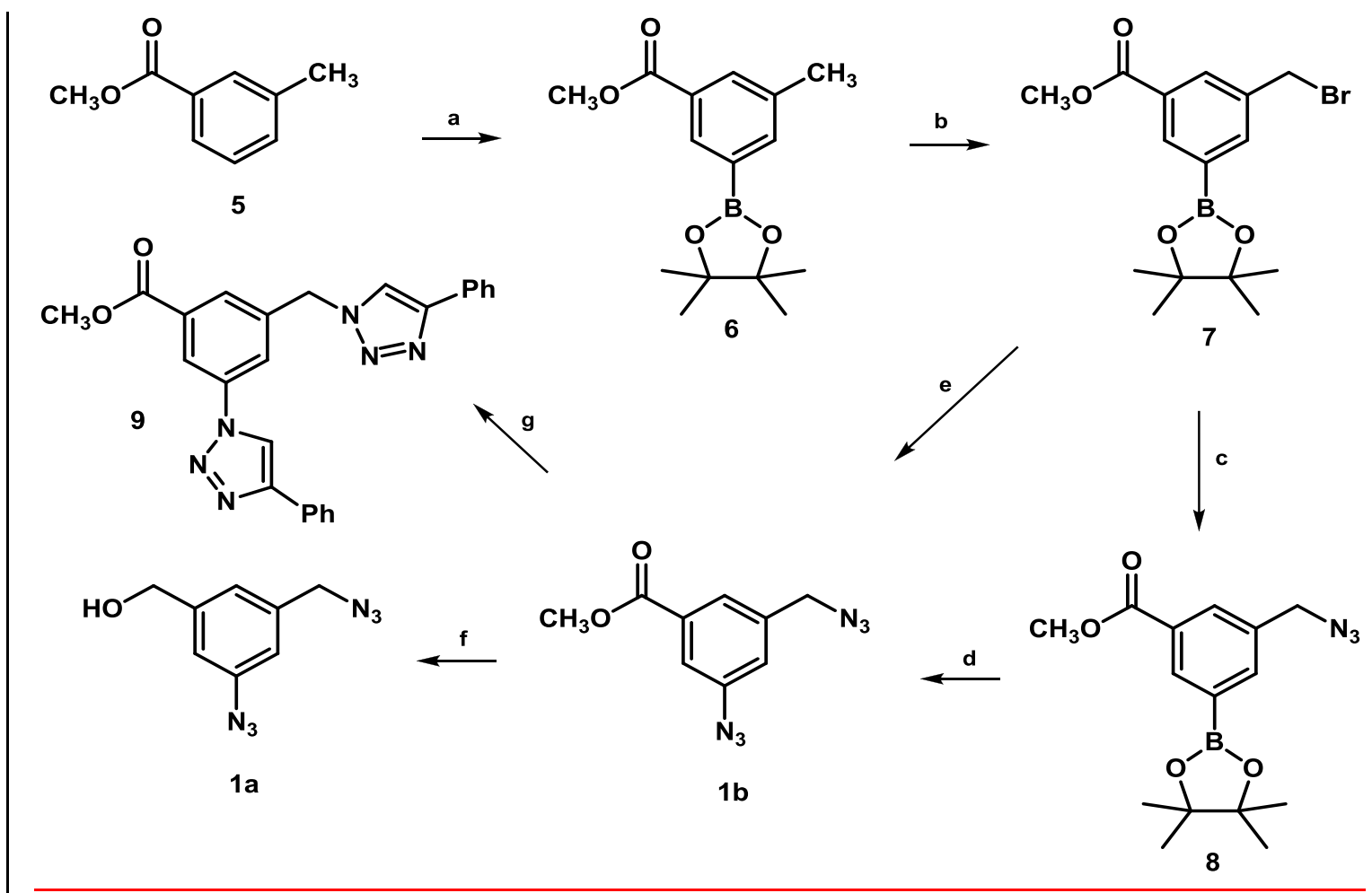

Scheme 1. Alternate Synthesis of 1a. Reagents: (a) $\mathrm{B}_{2} \mathrm{Pin}_{2}$, [COD(OMe)Ir $]_{2}$, dtbpy, hexane; (b) NBS, $\mathrm{Bz}_{2} \mathrm{O}_{2}, \mathrm{CCl}_{4}$; (c) 1.5 eq. $\mathrm{NaN}_{3}, \mathrm{MeOH}$; (d) 1.5 eq. $\mathrm{NaN}_{3}, 0.1$ eq. $\mathrm{CuOAc}, \mathrm{MeOH}$; (e) 3 eq. $\mathrm{NaN}_{3}, 0.1$ eq. $\mathrm{CuOAc}, \mathrm{MeOH}$; (f) 4 eq. DiBAH (1M in hexanes); (g) ${ }^{18} 2$ eq. $\mathrm{PhC} \equiv \mathrm{CH}, 0.4$ eq. sodium ascorbate, 0.1 eq. $\mathrm{Cu}_{2} \mathrm{SO}_{4}, \mathrm{CH}_{3} \mathrm{CN} / \mathrm{H}_{2} \mathrm{O}$.

Treatment of azido-boronate $\mathbf{8}$ with sodium azide in the presence of catalytic copper acetate smoothly led to the known bis-azido-ester $\mathbf{1} \mathbf{b}^{[4]}$ in good yield. To further optimize this process, bromide 7 was directly reacted with 3 equivalents of sodium azide in the presence of copper acetate to afford $\mathbf{1 b}$ in $65 \%$ yield without any intervening chromatography. Since the azide products produced no parent ion under standard MS conditions, further structure proof for $\mathbf{1 b}$ was obtained by reacting this compound under standard Huisgen conditions to give the bis-adduct 9. Although the ester $\mathbf{1 b}$ has been coupled via the Staudinger-Bertozzi methodology to give amide-linked probes, ${ }^{[17]}$ our work required the corresponding ether linkage arising from coupling of our protein- 
binding entity to the benzyl tosylate. Through the action of diisobutylaluminum hydride, ester $\mathbf{1 b}$ was reduced to the desired alcohol $\mathbf{1 a}$ in $74 \%$ yield from which the tosylate or mesylate intermediate can be accessed as per literature. ${ }^{[4,10]}$

\section{CONCLUSION}

This alternate route provides probe 1a-c from easily available starting materials by taking advantage of the continuously evolving $\mathrm{C}-\mathrm{H}$ activation and boronate-functionalization protocols.

\section{ACKNOWLEDGMENTS}

This work was financially supported by the Potts Foundation (Grant No. 95440). We thank Professor Scott G. Franzblau (Director of ITR) for his support and encouragement and for his assistance in reviewing this manuscript. We also thank Raghupathi Neelarapu (Petukhov group, UIC) for an authentic sample of $\mathbf{1 a .}$

\section{SUPPORTING INFORMATION AVAILABLE}

Synthetic experimental details and ${ }^{1} \mathrm{H}$ and ${ }^{13} \mathrm{C}$ NMR characterizations of 1a, 1b, 6, 7 and 8. HRMS details for bis-'click' adduct of $\mathbf{1 b}(\operatorname{cpd} \mathbf{9})$ are also included.

\section{REFERENCES}

[1] Singh, A.; Thornton, E.R.; Westheimer, F.H. J. Biol. Chem. 1962, 237, 3006-3008;

Dubinsky,L; Krom, B.P.; Meijler, M.M. Biorg.Med.Chem. 2011, In Press, Corrected Proof, Available online 29 June.

[2] Campbell, P.; Gioannini, T.L. Photochemistry and Photobiology, 1979, 29, 883-892 and references therein. 
[3] Das, J. Chem. Rev. 2011, 111, 4405-4417.

[4] Hosoya, T.; Hiramatsu, T.; Ikemoto, T.; Nakanishi, M.; Aoyama, H.; Hosoya, A.;

Iwata, T.; Maruyama, K.; Endo, M.; Suzuki, M. Org. Biomol. Chem. 2004, 2, 637-641.

[5] Wright, A. T.; Cravatt, B. F. Chem. Biol. 2007, 14(9), 1043-1051.

[6] Hatanaka, Y.; Hashimoto, M.; Kanaoka, Y. Bioorg. Med. Chemistry, 1994, 2, 1367-

1373; Finn, F. M.; Stehle, C. J.; Hofmann, K. Biochemistry, 1985, 24, 1960-1965.

[7] Zhang, W.; Curran, D.P. Tetrahedron. 2006, 62, 11837-11865.

[8] Hosoya, T.; Hiramatsu, T.; Ikemoto, T.; Aoyama, H.; Ohmae, T.; Endo, M.; Suzuki, M. Bioorg. Med. Chem. Lett. 2005, 15, 1289-1294.

[9] He, B.; Velparthi, S.; Pieffet, G.; Pennington, C.; Mahesh, A.; Holzle, D.L.;

Brunsteiner, M.; van Breemen, R.; Blond, S.Y.; Petukhov, P.A. J. Med. Chem. 2009, 52, 7003-7013.

[10] Neelarapu, R.; Holze, D.L.; Velaparthi, S.; Bai, H.; Brunsteiner, M.; Blond, S.Y.; Petukhov, P.A. J. Med. Chem. 2010, 54, 4350-4364.

[11] Cho, J.Y.; Tse, M.K.; Holmes, D.; Maleczka, R.E.; Smith, M. Science, 2002, 295, $305-308$.

[12] Tzschucke, C.C.; Murphy, J.M.; Hartwig, J.F. Org. Lett. 2007, 9, 761-764.

[13] Harrisson, P.; Morris, J.; Marder, T.B.; Steel, P.G. Org. Lett. 2009, 11, 3586-3589.

[14] Although consistent reports of the yield of $\mathbf{6}$ were from 91-96\%, using non-Schlenk techniques and microwave irradiation, we were only able to obtain $48 \%$ yield on a multigram scale.

[15)] Feng, L.; Wang, Y.; Liang, F.; Xu, M.; Wang, X. Tetrahedron, 2011, 67, 31753180. 
[16] Grimes, K.D.; Gupte, A.; Aldrich, C.C. Synthesis, 2010, 9, 1441-1448.

[17] Saxon, E.; Bertozzi, C. R.; Science, 2000, 287, 2007-2010.

[18] Since the azido compounds did not show parent ions in their mass spectrum, a sample of $\mathbf{1 b}$ was treated under standard Huisgen (click chemistry) conditions ( 2 eq. phenyl acetylene, 0.4 eq. sodium ascorbate, 0.1 eq. copper sulfate, in $10 \%$ aq. acetonitrile stirred at room temperature for 2 days). The solvents were evaporated and the residue was purified via preparative thin layer chromatography $(0.5 \mathrm{~mm}$ plate) using ethyl acetate: hexanes (1:1) to give an analytical sample of bis-triazole 9. HRMS calculated for $\mathrm{C}_{25} \mathrm{H}_{20} \mathrm{~N}_{6} \mathrm{O}_{2}\left(\mathrm{M}+\mathrm{H}^{+}\right)$437.1721; found 437.1720. 